\title{
Artigos
}

\section{Um antropólogo no cartório: o circuito dos documentos}

Danilo César Souza Pinto A famigerada burocracia é objeto de queixas muito propaladas no Brasil. Reis (1990)

(UESB) num interessante artigo demonstra a impressão geral e difundida que se tem sobre a burocracia como um "mal atávico nacional" e como derivado de uma herança e colonização portuguesas. Muitos autores nas ciências sociais já abordaram o tema, desde os textos clássicos de Weber (1976), passando por autores americanos, como Merton (1971), Hall (1971) e Gouldner (1976), que adaptaram o esquema weberiano a um sistema com variáveis de racionalidade que possam ser medidas, até análises que se concentram no aspecto da dominação que uma administração burocrática acarreta e sustenta - como em Croizier (1963), Prestes Motta (1981) e Cardoso (1993). Há também debates internos à Ciencia Política entre algumas de suas escolas, como em Tullock (1965) e Downs (1967) que concebem o burocrata dos serviços públicos como um agente autointeressado em aumentar o orçamento da repartição quando atua junto aos políticos, que são clientela e patrocinadores. Em termos de estudos brasileiros, autores como Faoro (2001 [1958]) já contribuiram com suas análises. Jaguaribe (1958) inclusive classifica o Estado brasileiro como sendo um Estado cartorial.

Devido à peculiaridade dos instrumentos metodológicos de pesquisa e do que se poderia chamar de uma "visão antropológica", a sugestão é que uma etnografia da burocracia pode fornecer suas contribuições. Primeiramente, nas análises de tipo macro, peculiares das abordagens da ciência política e da sociologia, não se observa a presença de atores sociais concretos e suas relações, sejam elas de cunho mais pessoal ou de caráter mais impessoal. Nas análises sociológicas, os grandes referenciais são realmente "grandes", tais como classe social, elite dirigente, interesses coloniais ou grupos corporativos. O foco deste texto residirá no acompanhamento etnográfico do que Peirano (2002) chama de o "Estado em ação", na constante construção e atualização de seus mecanismos. Desse modo, o artigo procura incorporar uma sugestão que Magnani (2002) ${ }^{1} \mathrm{fez}$ aos estudos ubanos: produzir uma mudança de foco na análise pode acarretar, talvez, uma diversa visão e 
explicação sobre os fenômenos. Trata-se da tentativa de produção de um novo arranjo que seja construído a partir de um acompanhamento cotidiano, suas atividades diárias, o que pensam e como reagem diante da burocracia; todos esses aspectos, em diálogo com a teoria antropológica.

Prentendo tratar a burocracia de uma forma etnográfica, substancialmente por meio de minha pesquisa de campo em um cartório e seus desdobramentos, suas remissões, seus itinerários. Os dados referem-se aos poucos mais de 30 dias que frequentei o estabelecimento, entre julho e agosto de 2005. Dessa forma, entendo por estado não uma instituição, mas em analogia a Herzfeld (2005 [1997]), um modo de funcionamento por meio de reificações e naturalizações sobre os quais um olhar antropológico permite deslindar a transitoriedade e contextualidade dessas estratégias oficializantes. É por isso que compreender a burocracia como um dos mecanismos estatais passa por seguir o caminho de circulação dos documentos, pessoas e palavras: o "como" tendo preeminência sobre o "porquê". O que está em causa aqui é menos o Estado e mais o estado, entendido como múltiplo e polissêmico, "um complexo instável de gente e de funções" (Herzfeld 2005 [1997]: 20) através de seu regime comunicacional: a burocracia.

Este artigo está dividido em duas partes. Na primeira, discorrerei um pouco sobre minha entrada e condições de realização da pesquisa de campo num cartório do interior de São Paulo. Cartório no Brasil é muitas vezes entendido como o próprio sinônimo de burocracia. Na segunda, darei um tratamento teórico aos dados com vistas a refletir sobre alguns aspectos da burocracia e seu modus operandi à luz desses dados. Minha análise é tributária, principalmente, de alguns desdobramentos da teoria de Latour $(2000,2004)$ sobre a ciência e o direito.

\section{ALGUNS ESCLARECIMENTOS PRELIMINARES SOBRE CARTÓRIOS}

Existem cartórios no Brasil desde o período colonial. Num esforço para consolidar sua conquista na América, povoar e administrar seu território, sem grandes custos para a Coroa, Portugal organizou um sistema de doação de capitanias hereditárias, dividindo o território em 12 partes. Ao capitão donatário foi concedido o direito de demarcar e tomar posse de terras, doar sesmarias, enfim, administrar. Isso implicava a nomeação de funcionários, dentre eles os tabeliães.

As funções dos cartórios, malgrado sua especialização e diversificação, permanecem basicamente as mesmas desde o período colonial². Cabe ao cartório registrar e arquivar ações ou negócios realizados entre particulares, ou entre particulares e o Estado. Registrar acarreta, primeiramente, dar autenticidade ao documento, tornando o seu conteúdo e data irrefutáveis. Esse ato também dota o documento de eficácia legal. Isso quer dizer que, juridicamente, ele passa a garantir, às partes envolvidas bem como a terceiros, o cumprimento dos direitos e obrigações que descreve. A publicidade, no sentido de impedir a ocultação dos negócios, fornecendo a terceiros, a quem seus efeitos porventura possam vir a atingir, um meio seguro de pesquisa e ciência do registro, também é implicação do registro.

A Constituição Brasileira de 1988, em seu artigo 236, dando tratamento igualitário aos Tabelionatos de Notas e aos Cartórios de Registro, passou a chamá-los de Serviços Notariais e de Registro, uma maneira de desvincular 
esses serviços do emblema "cartório", que possui conotação pejorativa, através da associação entre cartório e hereditariedade. Tal associação, que vincula um tabelionato a uma família, é exemplo contumaz do que Schwartz (1979) chama de "abrasileiramento da burocracia", isto é, a interpenetração da burocracia à rede de parentesco e relações pessoais, integrando os burocratas e a própria burocracia dentro do esquema de apadrinhamento e sistema de poder. Pode-se tratar os termos tabelionato, cartório e serviços notariais quase como sinônimos por entender-se que todas elas são formas utilizáveis.Todavia, há detalhes importantes que se deve reter: a Constituição se refere a serviços notariais em contraposição a cartório e, como já disse, isso não é por acaso. O lugar onde realizei a pesquisa de campo se autodenomina tabelionato, e é senso comum entre os usuários que se trata de um cartório. $\mathrm{O}$ termo "serviços notariais" refere-se a o plano mais constitucional em contraposição a "cartório", um termo mais geral e indiferenciado; por fim, "tabelionato" designa o local específico onde realizei a pesquisa.

Os serviços notariais concedidos a particular atualmente no Brasil são de seis diferentes tipos, podendo funcionar em conjunto ou separadamente dependendo da demanda e da cidade em que se localizam. O serviço notarial onde realizei pesquisa de campo ${ }^{3}$ englobava duas atividades principais: era um tabelionato de nota, responsável por procurações, escrituras, reconhececimento de assinaturas e autenticação de documentos, e um tabelionato de protestos, que lavra os documentos de dívidas. De forma indireta, também abordarei os serviços do Tabelionato de Registro de Imóveis, o qual registra e averba atos relativos a imóveis, pois são serviços que dialogam constantemente.

\section{UM ANTROPÓLOGO NO CARTÓRIO}

O $1^{\circ}$ Tabelionato de Protestos localiza-se numa ampla avenida, uma das principais da cidade, e faz vizinhança com outro de forma simétrica, o $2^{\circ}$ Tabelionato de Notas e Protesto, constituindo concorrência. Isso se apresenta como um motivo que explica a rapidez nos serviços, pois como me informou um escrevente: “Temos de ser rápidos aqui, porque se demorar os clientes podem se dirigir ao tabelionato do lado. O negócio é não deixar acumular fila." Essa é uma imagem destoante daquela que se tem de organizações burocráticas que prestam serviço público. Uma vez que alguns cartórios são concessões estatais a particulares, há uma transformação deste e outros tabelionatos em empresas que visam à produtividade e ao lucro.

Minha estratégia para viabilizar a pesquisa de campo foi a utilização de um intermediário 4 . Um parente, corretor de imóveis numa cidade média (cerca de 150 mil habitantes) do interior de São Paulo na qual se localiza o cartório, foi quem me facilitou o início da pesquisa de campo. Como eu sabia de sua amizade com tabeliães, devida a sua profissão, pedi a ele que conversasse com o tabelião e pedisse para que me permitisse passar um período no tabelionato, ao que ele se prontificou de imediato, dizendo, inclusive, que havia pouco tempo assumira um novo tabelião, "homem inteligente e honesto", que lhe oferecera disponibilidade na execução de qualquer favor que precisasse. 
Quando fui apresentado, o tabelião pensara que se tratava de um estagiário de Direito, o que fazia mais sentido, pois não é muito comum antropológos trabalharem em cartórios ${ }^{5}$, mas expliquei que era um pesquisador tentando entender a burocracia daquele lugar. Ele não gostou do termo, pois "o que fazemos aqui não tem nada de burocracia". Como essa é uma palavra pejorativa para muitos, tratei logo de me desculpar. Passado esse desentendimento inicial, explicou-me que trabalhara desde cedo em um tabelionato, primeiramente como office-boy e depois da faculdade de Direito, como tabelião responsável por uma cidade menor. Adriano ${ }^{6}$ era o primeiro concursado que assumia aquele tabelionato. $\mathrm{O}$ anterior era designado ${ }^{7} \mathrm{e}$ havia recebido a concessão como "herança" de seu pai. Assumido o posto, resolveu manter os funcionários do lugar e contratar duas pessoas que o assessoravam em sua antiga empresa. Com exceção do tabelião, formado em Direito e único concursado, os demais funcionários não têm formação superior, posto que a exigência mínima é o curso de escrevente, geralmente realizado após a contratação. Adriano disse pretender fomentar e valorizar as iniciativas de sua equipe quanto a participação no curso de Direito, o que, para ele, melhoraria o serviço prestado e os atualizaria quanto aos procedimentos mais recentes.

Terminada minha estadia no tabelionato, iniciei um acompanhamento junto a pessoas que necessitassem requerer algum documento, procurando assim expandir o "circuito" (num uso particular da categoria promovido por Magnani 2002) relacionado ao cartório, já que os rumos que a pesquisa foi tomando confirmaram a necessidade de sair detrás dos balcões e ir acompanhar o caminho que os documentos faziam para ter um melhor entendimento do modus operandi dessa burocracia. Isso parece configurar uma necessidade aos pesquisadores que buscam entender sistemas dessa natureza. lubel (2009) em sua etnografia sobre o NUCRIA também percebeu que teria de se deslocar entre instituições para compreender melhor o funcionamento dessa comunicação, o que vem a ratificar o aspecto retroalimentativo que constitui o sistema - e será tratado adiante. A perpétua remissão burocrática leva o pesquisador invariavelmente para fora de sua aldeia no seguimento desse fio de Ariadne burocrático.

Apesar do deslocamento, a pesquisa de campo se deu, fundamentalmente, num Tabelionato de Notas e Protestos. As informações contidas no artigo são, em grande medida, tributárias desse tipo de instituição. Os procedimentos em detalhe se referem ao Tabelionato de Notas e Protestos, embora eu pense que as descrições aqui contidas possam, talvez, inspirar discussões sobre o modus operandi da burocracia no Brasil.

\section{O ITINERÁRIO BUROCRÁTICO}

A pesquisa no tabelionato foi importante para se perceber que a burocracia ativa uma circulação, um "circuito", de pessoas, documentos e palavras. A pesquisa "atrás do balcão" do tabelionato fez ver o quão interessante seria observar as histórias das pessoas que procuravam o cartório, pois os documentos do tabelionato de notas são sempre um meio cujo objetivo encontra-se alhures. O tabelionato emitia documentos necessários 
à consecução de contratos, negócios e afins. Para o entendimento do que estou a dizer, é preciso discorrer sobre algumas situações muito emblemáticas que acompanhei. Como o meu acesso ao tabelionato se deu por "intermédio" de um corretor de imóveis, as situações envolvendo negócios com imóveis por força do contexto acabaram por merecer melhor atenção. De qualquer forma, essas situações são ilustrativas do funcionamento dessa burocracia cartorial. Relatarei a seguir três exemplos de situações que acompanhei.

\section{1) Catalisadores, tradutores e conhecidos}

Um senhor que acabara de se aposentar resolveu investir o dinheiro que recebera em um imóvel e um jovem casal queria vender sua casa ao aposentado com o intuito de comprar outra. Antes de se reunirem comprador e vendedor diante do escrevente para redigir o contrato de compra e venda, o corretor de imóveis contratado realizou todo um trabalho preliminar à assinatura. Para executar a venda de um imóvel, depois de toda a negociação de valor, ele percorreu um complexo de instituições burocráticas, com o intuito de verificar se não havia nenhuma pendência tanto com o imóvel quanto com a pessoa que o desejava vender. Em todas essas instituições foram emitidos documentos, com seus devidos carimbos e assinaturas. Além disso, nesse contrato ainda constaram números tais como o do Registro Geral (RG) e do Cadastro de Pessoas Físicas (CPF) ${ }^{8}$, pelo menos, dos contratantes. Assinado o contrato de venda no tabelionato de notas (e para que isso ocorresse os contratantes abriram ficha ${ }^{9}$ no tabelionato, portando RG e CPF), o corretor ainda se dirigiu ao Tabelionato de Registro de Imóveis, onde alterou o proprietário do imóvel em questão. Esses documentos foram juntados e citados no contrato de compra e venda.

O corretor, portanto, além de realizar a venda, deve ser perito em oficializá-la. De posse dos documentos pessoais e do imóvel, ele percorreu o cartório de registro de imóveis (para verificar se não havia nenhuma pendência legal com o imóvel), o $1^{\circ}$ e $2^{\circ}$ registro de notas (para averiguar se não existia nenhum protesto contra a pessoa que desejava vender o imóvel), a Justiça Federal (para corroborar se havia algum processo contra a proprietária), a Justiça do Trabalho (para saber se não existia nenhuma pendência trabalhista com a proprietária) e a Prefeitura (para pedir uma Certidão de Existência do Imóvel).

Para realizar qualquer ação que tenha validade diante do Estado, tem-se que percorrer um itinerário burocrático. Uma ação oficial sempre remete a outras ações oficiais para ter validade. A fim de realizar uma venda em um cartório, que é uma instituição, embora particular, avalizada pelo Estado, faz-se necessário remeter a muitas outras ações que já foram realizadas diante do mesmo Estado. Toda ação legal começa pelos documentos pessoais. O início dessa "linguagem oficial" principia sempre com o pedido acerca do RG e CPF, quando se trata de ações mais simples, como reconhecer a assinatura de um contrato. Quando são ações que envolvem mais elementos, como no caso de venda de imóvel - que, além de envolver comprador e vendedor, também requer a veracidade na propriedade do imóvel - o número de documentos e organizações públicas envolvidas aumenta significativamente. Um Atestado de Dependência Econômica ${ }^{10}$, por exemplo, requer apenas os documentos do dependente e do provedor; um Contrato de Venda Imobiliária necessita, 
além dos documentos de comprador e vendedor, documentos remetidos pela Prefeitura, Justiça do Trabalho, Justiça Federal e Tabelionato de Registro de Imóveis. Para ser fabricado um documento sempre remete a outros documentos. Isso instaura uma comunicação oficial, isto é, por documentos. A linguagem aqui é a do oficial, uma linguagem que o Estado entende e dissemina.

E toda essa complicada linguagem dos documentos tem como decorrência a emergência de profissionais peritos. No caso relatado, além do escrevente e do tabelião, que produzem o contrato, há a figura do corretor, que atua como um perito detentor do conhecimento sobre os trâmites necessários para a consecução do negócio. Ele, além de ser aquele que detém conhecimento sobre o mercado imobiliário, é um agente que sabe o circuito que deve ser percorrido para a validade do contrato de compra e venda. Quando um negócio desse tipo é realizado com corretor, comprador e vendedor se abstém de percorrer o itinerário, visto que este será realizado por um perito.

No Brasil é institucionalizada a profissão de despachante, cujo trabalho, entre outros, consiste em saber lidar com a burocracia estatal relacionada a documentos de veículos, dentre outros. Da Matta $(1983,1985)$ trata da questão, mostrando que esse papel é típíco de uma sociedade que combina elementos republicanos com aristocráticos, valor indivíduo e valor pessoa. Para acessar serviços públicos e universais, utilizam-se intermediários. O corretor seria mais um intermediário, perito em trâmites burocráticos, e a própria estratégia de pesquisa parece comungar dessa lógica, uma vez que a viabilidade dela dependeu de um contato de mediação.

Além de todo esse procedimento mais geral conduzido pelo corretor e pelo escrevente e tabelião, havia particularidades nessa situação. $O$ casal que estava vendendo o imóvel tinha a intenção de comprar uma casa financiada por um banco público. Entretanto, por uma exigência burocrática, para liberação do Fundo de Garantia ${ }^{11}$ era necessário não ser proprietário de nenhum imóvel. Após a venda da casa, o prazo de registro do novo proprietário no Tabelionato de Imóveis é, em média, de dois meses no munícipio. Entretanto, o vendedor tinha pressa, pois já achara a casa que desejava comprar e não queria perder o negócio. Então, como conhecia um funcionário do tabelionato de imóveis, ele conseguiu que essa transferência saísse na mesma semana, mediante, é claro, o pagamento de uma taxa extra. Ou seja, ao agregar um conhecido e mais algum dinheiro, ele conseguiu agilizar, acelerar os prazos da burocracia do Tabelionato de Registro de Imóveis. Essa rapidez foi possível devido a um esquema entre o interessado em agilizar, o escrevente do tabelionato de notas e o de imóveis. Essas operações foram realizadas no tabelionato concorrente ao que realizei a pesquisa e que tem fama de ser mais flexível com as normas. Coincidência ou não, o tabelionato de maior rigor é administrado por um tabelião concursado e o concorrente, mais flexível, por um designado.

Afora o trabalho de tradutor do corretor, o Tabelionato de Registro de Imóveis também teve de funcionar como "catalisador" na oficialização do procedimento. Isso é muito comum, já que a burocracia é cheia de prazos. Devido ao imenso volume de documentos que intituições como o cartório produz, é mister que para oficializar algum procedimento encontrem-se prazos. No caso do Tabelionato de Registro de Imóveis, antes do oficializar uma trasanção, há todo um trâmite interno e externo (como pedidos de outros documentos a outras instituições) que requer algum tempo antes da lavratura. Entretanto, esses rígidos prazos podem ser 
flexibilizados, como é de senso comum no Brasil quando se apresenta a figura do conhecido. Ele é aquele que vai, a fim de cumprir os prazos, passar o procedimento à frente na fila ou negligenciar algum trâmite mais formal, baseando-se na confiança e no fator conhecimento para que alguma ação seja oficializada. Nesse caso, o conhecido, mediante o pagamento de uma taxa, realizou as averbações necessárias para mudar o proprietário do imóvel em dois dias, catalisando o itinirerário e cortando fila de outros serviços que já se haviam apresentado. Pode-se observar, por essa descrição, como uma imagem burocrática de estabilidade e rigor é manuseada no contexto da ação. O uso cotidiano subverte o código permanentemente. A prática real subverte constantemente a norma, utilizando-se da forma discursiva desta, de estratégias oficializantes. É uma forma de operar que cria dificuldades para vender facilidades (Herzfeld 2005 [1997]).

\section{2) Metrologia: segurança e responsabilidade}

Um casal de terceira idade desejava vender um sítio que possuía em uma cidade mineira. Como o imóvel estava em outra localidade, a transação deveria ser validada na cidade onde se localizava o imóvel. No entanto, o casal vivia na cidade paulista em que realizei a pesquisa. Para evitar o transtorno de a mulher também ter de se dirigir ao cartório do outro município, ela fez uma procuração ${ }^{12}$ (para foro em geral) em nome do marido para que este, sozinho, pudesse assinar o contrato. No entanto, além da esposa, ele levou todos os filhos para a emissão de uma Certidão de Anuência para que estes os autorizassem a realizar a venda. $O$ escrevente achou essa situação estranha e chamou o tabelião, que explanou, segundo sua visão, sobre a desnecessidade da produção dessa certidão, já que os pais se encontravam "lúcidos e capazes". Todavia, o proprietário do imóvel informou ao tabelião que o documento tinha sido uma exigência do cartório mineiro onde seria concretizado o negócio; ao que ele, contrariado, disse poder resolver. Dirigiu-se ao escritório e telefonou para o tabelionato mineiro. Minutos depois retorna, deveras irritado, dizendo que o colega mineiro estava equivocado, pois "duas pessoas lúcidas estão aptas a realizar qualquer negócio independente da vontade de seus filhos". Por fim, teve de produzir a Certidão de anuência, caso contrário, o atual proprietário não conseguiria realizar o negócio.

Além de enxergar esse caso como um tipo de "desentendimento burocrático", cabe ver nessa situação a "dimensão tutelar". A "tutela" funciona como um modelo de "controle e alocação diferencial e hierarquizada de populações, para as quais se criam estatutos diferenciados e discricionários nos planos jurídicos e/ou administrativo" (Souza Lima 2002) com a finalidade de pacificar possíveis zonas de conflito ${ }^{13}$. No evento é interessante observar que, embora a solução encontrada pelo tabelionato mineiro não esteja em nenhum manual - já que o casal que desejava vender o imóvel fora considerado capaz (isto é, lúcido) pelo tabelião paulista e, provavelmente, também o fosse pelo mineiro -, o saber prático do tabelião o informava de que era assim (pedindo a Certidão de Anuência dos filhos) que ele deveria proceder. Para evitar possíveis problemas futuros com essa venda, o tabelionato mineiro criou uma situação especial, na qual não bastava os proprietários (indivíduos como foco primordial de ação judicial) desejarem vender o imóvel; a responsabilidade da ação recaía 
também sobre a família (filhos). Ocorreu, então, uma espécie de questionamento da capacidade jurídica desses indivíduos frente ao Estado, gerando, assim, um procedimento especial que se desdobrou em desentendimento burocrático devido a dois entendimentos diferentes com relação aos procedimentos a serem adotados.

São classificados como plenamente capazes indivíduos maiores de dezoitos anos e que sejam considerados pelo tabelião e pelo escrevente como lúcidos. O tabelionato, portanto, além de promover a autenticidade nos atos, deve também observar sua pertinência segundo as regras estatais, que limitam a capacidade apenas aos indivíduos maiores de dezoito anos e que aparentemente estejam gozando de boa saúde mental. A afirmação da lucidez é importante já que a função do cartório é dar publicidade aos atos realizados pelas partes segundo seu livre consentimento. No caso em pauta, o tabelionato mineiro estava questionando a lucidez do casal. Por serem idosos, ele estava tentando se proteger de eventuais futuros conflitos com os filhos devido a algum questionamento que poderia ser feito em termos de herança no futuro. Pelo menos, essa foi a interpretação do tabelião e escrevente paulista sobre a exigência dessa certidão suplementar.

$\mathrm{O}$ argumento do cartório com relação ao porquê da apresentação de tantos documentos originais, 0 porquê de tanta papelada emitida por prefeitura, outros cartórios, justiça federal, etc., reside na responsabilidade que o cartório possui como árbitro e consumador das diversas ações legais pelas quais possui prerrogativas, ou seja, a fé pública que o Estado lhe outorga o coloca também em posição de arcar com eventuais erros. A responsabilidade que o cartório tem na transação acompanha a segurança dos negócios efetuados em cartório. 0 par responsabilidade/segurança foi apresentado a mim diversas vezes como o motivo de se seguir e o perigo de não se seguir devidamente as formalidades nos atos, pois, se o cartório não segue adequadamente os procedimentos legais, pode arcar com as responsabilidades caso alguma das partes venha a reclamar. E se elas não registram o negócio em cartório não têm garantia de terem efetuado um negócio seguro, já que não realizado aos olhos do Estado e de seus instrumentos legais. Tudo deve ser feito seguindo as mais diversas formalidades para resguardar o tabelião e o escrevente da responsabilidade das ações e proteger a segurança dos negócios, ainda que negócio totalmente seguro seja impossível, como informa Adriana Magalhães:

Muitos dizem que o único modo teoricamente seguro de comprar qualquer imóvel no Brasil seria tirar todas as certidões de todos os donos do imóvel nas últimas duas décadas anteriores à compra, em todas as esferas do direito (trabalhista, cível, penal, fiscal.) e em todos os estados e municípios do país. Como estamos falando de dezenas de milhares de certidões, sabemos que a busca por essa segurança absoluta inviabilizaria qualquer negócio (...) (Magalhães 2006, grifos nossos)

É na veemência de se proteger e de dar segurança que ocorrem as confusões e desentendimentos com relação às normas. Desentendimentos sobre procedimentos formais são corriqueiros. Pude observar isso com clareza principalmente porque no tabelionato em que fiz minha pesquisa de campo acabara de assumir um novo tabelião, que estava adaptando os procedimentos ao seu modo. Cansei de ouvir frases como: "Cada tabelião tem um estilo"; "Cada tabelião trabalha de um jeito"; "Estou adaptando esse modelo 
(de escritura) ao modelo do Adriano"; “Um tabelião prefere carimbo, outro selo. Um gosta de espaço em branco para a assinatura; outro, o espaço tem que ser preenchido"; "Sempre há o bom senso". Essa situação de "confusão" com relação aos procedimentos estava viva e saltava aos olhos no tabelionato, até mesmo por ele se encontrar em um momento de transição. Os escreventes mais antigos são os que falavam com mais autoridade, pois já haviam passado por três tabeliães diferentes. Quando diziam algo sobre a diferença nos procedimentos, frequentemente acrescentavam: "Mas se você falar que cada tabelião trabalha de um jeito, ele (o tabelião) não vai gostar: Vai dizer que a lei é uma só, igual pra todos...".

Mesmo dizendo que todos os tabelionatos deveriam trabalhar igualmente, pois a norma é uma só, no próprio desentendimento entre os dois tabelionatos, Adriano demonstrou sua insatisfação pelo fato de determinados tabelionatos não seguirem a norma como ele. O interessante é observar que, dentro de algumas exigências mínimas, todo cartório tem alguma liberdade para criar procedimentos, tanto acima ou abaixo da norma. Digo "acima" quando estou a me referir ao exemplo relatado ou até mesmo a diferenças que encontrei no procedimento desse tabelioanto com relação ao Manual do Tabelião - que um escrevente já me adiantara, ninguém consulta - ou mesmo aos cursos que os escreventes fizeram e a cujas apostilas tive acesso, as quais informavam, por exemplo, que para uma pessoa abrir firma era necessário somente a apresentação do RG (ou outros documentos que o substituem); todavia, esse tabelionato exigia a apresentação conjunta do CPF. Quando perguntei sobre esse diferença de procedimento com relação à apostila, os escreventes ignoravam minha pergunta ou o fato de na apostila não constar tal exigência.

E quando digo criação "abaixo da norma" me refiro a casos abundantes nos quais o tabelionato não realizava dados procedimentos, mas indicava à pessoa o tabelionato ao lado, pois: "Quem sabe eles não fazem?". O exemplo mais corriqueiro desse tipo de fato ocorria quando uma pessoa chegava com apenas as assinaturas de um contrato. O escrevente dizia não poder reconhecer firma só da folha das assinaturas: era necessária a apresentação do contrato integral. E nisso ele estava de acordo com o manual, mas a sua experiência o avisava de que outros cartórios poderiam praticá-lo, então, ele indicava: "Aqui nós não fazemos assim, mas dá um pulo no do lado, quem sabe eles não fazem este serviço para você?".

É na observação de caráter etnográfico do funcionamento cotidiano de instituições desse tipo que é possível perceber a relação entre instabilidade e estabilidade estatal. A impressão que o tabelião quer passar é a de que existem rígidas normas formais para a realização de uma tarefa pública. E isso é somente verdade se considerarmos que essa rigidez é variável. Um tabelião se irrita com outro, pois pensa que a norma é uma só e que todos deveriam segui-la como ele. No entanto, do ponto de vista do tabelião criticado a norma está sendo cumprida. Todos têm essa impressão e defendem a estabilidade e permanência dos procedimentos, mas o fazem de maneiras particulares. Isto demonstra a instabilidade dentro de uma promoção de imagem estável, além de promover desentendimentos burocráticos, os quais serão apagados (estabilizados) após a concretização da ação pública escrita em documento. 
O que chamei de desentendimentos burocráticos ou variações de tabelião para tabelião, a etnografia informou que ocorre, normalmente, devido ao tabelionato querer se resguardar ao máximo da responsabilidade dos atos. Para tanto, pedem-se muitos documentos para se apoiar num código oficial e já aceito, produzindo, assim, o novo documento, acrescentando mais um formulário à massa de formulários existente. Portanto, é através do par responsabilidade/segurança enunciado pelos nativos que devemos buscar a explicação para os "desentendimentos" e para o pedido de um número grande de documentos. A burocracia funciona como uma linguagem, na qual se busca, ao produzir uma informação, atá-las a outras que, em algum momento, foram produzidas de modo similar. Todavia, não é qualquer informação que serve. Ela deve ser oficial, passar por todo um ritual, por meio do qual deixa de ser uma informação qualquer e passa a se constituir em documento; não mais um papel escrito qualquer e sim um papel que possui legitimidade em existir, um veredicto, uma palavra de Estado, um efeito produzido pelo sucesso no trâmite. O par responsabilidade/ segurança, de acordo com essa leitura, seria a resposta nativa do cartório ao mecanismo de funcionamento da linguagem burocrática, o qual opera através da acumulação de informações oficiais.

Latour, em seu livro Ciência em ação, denomina o empreendimento que traz as coisas "de fora" para "dentro", ou seja, conduz o que não está classificado para o papel, em formulário, de "metrologia". Segundo suas palavras:

Metrologia é o nome desse gigantesco empreendimento para fazer que o mundo de fora passe a ser um mundo de dentro do qual fatos e máquinas possam sobreviver. (...) os cientistas constroem suas redes iluminadas conferindo ao mundo de fora a mesma forma de papel que têm seus instrumentos no mundo de dentro. Em ambos os casos, o resultado é o mesmo: pode-se viajar para muito longe sem sequer sair de casa (Latour 2000: 409).

Com a burocracia, mutatis mutandis, é assim que ocorre. A "metrologia" na burocracia é o empreendimento executado pelo Estado através de seus agentes com o intuito de classificar tudo que ocorre nos limites de seu território. No cotidiano, é comum utilizar as mais diversas cadeias metrológicas; contudo, dificilmente percebe-se o uso: a área de uma casa, o valor de um salário, a temperatura de momento e, no caso dos documentos, o local de nascimento, o nome de uma pessoa, a data de aniversário. É claro que para saber onde meu avô nasceu ou qual o meu nome, não há necessidade nenhuma de se remeter a documentos. No entanto, se essas perguntas forem feitas do ponto de vista de um centro ou do interior de uma rede, as informações dadas por parentes e amigos serão insuficientes. Se tais informações forem solicitadas por um cartório ou por um policial, os documentos serão imprescindíveis. A informação na "rede burocrática" só circula após se transformar em informação burocrática: tem de ser redigida no papel e reconhecida como oficial por um agente do Estado. Portanto, se expandirmos o significado de metrologia para além de constantes científicas básicas até a transformação em formulários de um número máximo de coisas do exterior, chegamos à burocracia e à sua circulação de informação em rede, sendo esta avalizada e incentivada pelos mecanismos de controle estatais. 


\section{3) Responsabilização: quando as formalidades não são seguidas}

Há dois tipos de reconhecimento de firma produzido pelo tabelionato de notas: o reconhecimento por semelhança e o reconhecimento autêntico. No primeiro, o escrevente compara a assinatura que a pessoa depositou na ficha com aquela que se quer reconhecer como legítima, sendo dispensável a presença do assinante perante o escrevente; no segundo, a pessoa assina na frente do escrevente (tanto onde se quer reconhecer como autêntico como numa ata do cartório), que ratifica, por meio de um selo, a legitimidade da mesma. Segundo os escreventes e os manuais consultados no tabelionato, o reconhecimento autêntico é o reconhecimento por excelência. Dependendo do tipo de ação envolvido no reconhecimento, apenas ele é válido: é o caso da venda de automóveis.

Um dos escreventes do tabelionato, certa vez, ao reconhecer uma venda de automóvel na qual seu irmão figurava como vendedor, "esqueceu-se" de anotar na ata de reconhecimento de firmas autênticas a assinatura do irmão; isto é, sem a presença do assinante, ele reconheceu a assinatura do recibo do veículo como autêntica, quando na verdade o procedimento fora o de reconhecimento por semelhança. Segundo o relato, de boa-fé e confiando em seu irmão, procedera dessa forma para "facilitar a vida" do parente a fim de que este não precisasse se dirigir ao tabelionato para ratificar a transação. Entretanto, passado algum tempo o irmão questionou na justiça o negócio, e, como os procedimentos não foram os prescritos, o juiz considerou o tabelionato culpado, o qual teve de ressarcir os danos. No final, quem arcou com os custos foi o próprio escrevente e não o tabelião. Os escreventes me diziam que a responsabilidade maior é do tabelião, por isso, em caso de dúvida sobre algum procedimento, deve-se recorrer a ele. O serviço notarial age como intermediário nas negociações (acordos, contratos) entre pessoas físicas ou jurídicas. Atribui veracidade às coisas e arca com as consequências se aquilo for dado como falso na justiça. Esse relato foi me feito repetidas vezes para exemplificar a responsabilidade que possui um escrevente, o tabelião e o serviço do cartório, que é imputado pelas falhas. Nunca me disseram qual dos escreventes havia cometido o erro.

\section{CONSIDERAÇÕES GERAIS SOBRE A BUROCRACIA}

De acordo com a terminologia latouriana, a burocracia se localiza na posição de "central de cálculo", sendo responsável pelo acúmulo de formulários que permitam a apropriação do mundo de fora num mundo de papel. Exige a necessidade de manuseio de formulários e formulários de formulários, podendo, assim, controlar, ou pôr em rede, informações como a história de cada indivíduo, a história de cada imóvel, as transações que cada pessoa realiza durante sua vida, etc. No caso específico do Tabelionato de Notas, quando se alude à responsabilidade do cartório e à segurança dos negócios como motivo para pedir formulários, trata-se, segundo esta leitura sobre a comunicação burocrática, de uma explicação nativa do mecanismo de circulação de informação em rede. Isto é, para a sustentação da rede informacional e sua ampliação é necessário que 
documentos sempre remetam a documentos, informações oficiais a informações oficiais. É por isso que, a fim de abrir ficha em cartório, há a necessidade de apresentação do RG e, às vezes, do CPF; para vender um imóvel é necessário buscar vários documentos oficiais de vários órgãos governamentais.

Não basta dizer que a área de uma casa é de cinquenta metros quadrados; quem deve dizer isso é um documento da Prefeitura (Atestado de Existência, por exemplo) que está localizado no interior da rede de comunicação, sendo uma informação oficial. No caso do tabelião mineiro que pede anuência dos filhos para os pais venderem o imóvel, trata-se de ver no acúmulo de informações - no caso, os documentos dos filhos com suas respectivas autorizações - um meio de garantir maior segurança ao contrato e de resguardar o tabelionato, já que ele produzirá um formulário do formulário, ou seja, a sua informação (o contrato de venda) será o resultado da associação do RG - e de outros documentos pessoais - do vendedor, da mulher do vendedor, dos filhos do vendedor, do comprador, de documentos remetidos pela Justiça Federal, a Justiça do Trabalho, a Prefeitura e o Cartório de Imóveis, além do sinal público remetido pelo tabelionato paulista que validou as assinaturas.

Todavia, se para o tabelião, que fala por uma "central de cálculo", é importante o acúmulo de informações oficiais, para um cidadão que se dirige a uma "central de cálculo", os pedidos geram uma correria e perda de tempo em busca de documentos e são um verdadeiro empecilho à execução de suas vontades. O que ocorre aqui tem paralelo com a situação descrita por Latour no disparo de acusações do interior da rede sobre quem está fora. Se para quem está dentro as informações de fora são sempre insuficientes - como o guarda que, perguntando quem você é, pede seu documento -, para quem está fora é um verdadeiro problema fornecer informações às centrais de cálculo. Pode não haver nenhum grande problema em apresentar o RG em determinadas organizações, já que as pessoas se acostumaram a carregá-lo. No entanto, só de documentos pessoais básicos temos cinco - se considerados somente o Registro Geral, o Cadastro de Pessoas Físicas, a Carteira de Trabalho, o Reservista (para os homens) e o Título de Eleitor. Há inúmeros documentos que não temos sequer em casa, como o Registro de Imóvel; ou que têm validade como a Certidão negativa/ positiva de protestos. O que faz haver o conflito do qual resulta o xingamento "é tanta burocracia" (simétrico à acusação de irracional, no caso do discurso científico; ou insuficiente, vinda do interior da rede, no caso da burocracia) é a diferença de linguagem no encontro entre acusações. Na verdade, a acusação que torna o termo "burocracia" pejorativo, e que vingou no senso comum, tem origem no exterior da rede e se dirige para o interior. Basta pensar nas transações cotidianas. Para comprar qualquer coisa num mercado, o dinheiro do comprador, os produtos e a nota do vendedor (esta ainda pode ser dispensada) são suficientes. Agora, uma transação de imóvel lavrada em cartório não é tão simples assim. O controle do Estado é maior, logo a linguagem é mais burocratizada, o que instaura uma comunicação mais balizada e regulada pela linguagem escrita: a transação deve ser posta no papel com as minúcias que a caracterizam; deve ser designado o autor (mediador) do documento (que no caso é o tabelionato de notas); e o documento deve remeter a outros documentos considerados oficiais e que já passaram por tal processo em outros locais. Devido à necessidade de observação de todos esses procedimentos, nos quais o Estado se faz notar fortemente, a linguagem não 
sendo mais a linguagem cotidiana das relações, detona-se a acusação "é tanta burocracia", posto que se provoca uma inflexão na linguagem e nos modos de comunicação. Ela agora se tornou mais complicada. A palavra falada, o negócio boca a boca, não tem valor absoluto, pois o Estado deve se fazer sentir como mediador e como fornecedor da linguagem apropriada, uma linguagem "mais dura", como diria Latour, pois, além de alegação, ela deve ser uma verdade, reconhecida e legítima perante todos, pois registrada em órgão oficial.

Trocamos, então, a acusação de "mal atávico nacional" posta à burocracia por uma explicação que versa sobre a interseção entre linguagens diferentes. Da aparente "irracionalidade" que atrapalha o fluir das coisas no cotidiano, passamos a observar toda a racionalidade, no sentido de modo de funcionamento do sistema, desse tipo de comunicação muitas vezes incompreendido. O que ocorre, em suma, é o conflito entre uma linguagem, em que uma afirmação (ou poucas afirmações) já satisfaz, com outra que funciona como se uma única afirmação nunca bastasse: deve-se sempre recorrer a outras informações que confiram substância à nova ou amarrar afirmações à afirmação para torná-la "mais forte".

Se o Estado burocrático tem íntima ligação com a escrita (Goody 1986), pode-se observar - segundo minha etnografia, que é pautada pelas minhas observações no tabelionato, mas que também pode dizer um pouco sobre o modus operandi da burocracia estatal em geral - um descompasso referente ao encontro de diferentes dispositivos de comunicação. Para ser válida na burocracia, a informação, em primeiro lugar, precisa passar por todo um processamento que, além de ser escrito, deve ser reconhecido por agências estatais. Ou seja, a informação válida só pode sê-la se posta em documento segundo todo um linguajar técnico-jurídico que foi historicamente desenvolvido por especialistas, cujas informações remetam a outros documentos que também foram produzidos da mesma forma. Ela implica o acúmulo de informações oficiais, construído através de itinerários burocráticos. A informação necessariamente tem de ser inscrita em documento e de acordo com um processo que acarrete na impressão de homogeneidade e persistência histórica dos procedimentos. Disso deriva o desconforto de qualquer pessoa, não especialista, com relação a esse dispositivo. Ela funciona segundo suas próprias regras, as quais nem sempre são conhecidas e compartilhadas por todos.

É nesse sentido que se deve refletir sobre a categoria papelada - denominação genérica dos documentos no Brasil. Se nas organizações burocráticas, como uma delegacia, observa-se na parede o cartaz "Documentos necessários para requisição do RG", no qual se citam todos os documentos necessários para dar entrada na requisição. No CIRETRAN"14, por sua vez, observa-se o cartaz "Documentos necessários para a solicitação de licenciamento de veículo". Ao sair do âmbito da organização e entrar no discurso das pessoas que vão solicitar esses documentos, ocorre uma transformação no vocabulário: eles se transformam em papelada, necessária para obtenção de algo. A mudança de vocabulário denota o desconforto e descompasso de que venho falando. De documentos específicos como Certidão de Nascimento e Ficha de Identificação Civil necessários à obtenção do RG, passamos à papelada, isto é, uma pilha de documentos, muitas vezes parecidos entre si, ou que são referidos por siglas (RG, CPF, CNH, para ficar nos mais famosos), que se tem de juntar para requerer mais um documento que também entrará no conjunto papelada. 
Segundo a terminologia conceitual de Latour que estamos empregando, poderíamos dizer que documentos específicos (RG, CPF, procuração, escritura, etc.) são o material com que lidam os burocratas, aqueles que estão no interior da rede; já a papelada é o termo que as pessoas utilizam quando se dirigem às organizações. Se a teoria que está sendo utilizada aqui faz sentido quando se pensa na burocracia brasileira, se estou certo de que existe um linguagem peculiar no interior da rede e outra, também peculiar quando se pensa no exterior desta, em termos purificados - posto que essas linguagens se juntam no discurso (vide mediadores, catalisadores e conhecidos) -, faz todo o sentido pensar na equação (posição na rede/ vocabulário): interior da rede $=\mathrm{RG}$, certidão de nascimento, procuração, etc./exterior da rede = papelada. Ou seja, as pessoas acostumadas a lidar com os documentos, entendendo na prática as especificidades de cada um, referem-se a estes pelos seus respectivos nomes; no entanto, embora portem documentos, os que não participam cotidianamente da prática burocrática referem-se a eles como papelada, uma categoria genérica que classifica todos os documentos.

Essa duplicidade conceitual ilustra bem o que Herzfeld (2005 [1997]) chama de dissemia, que suscita, na obervação da intimidade cultural, a tensão entre o oficial e aquilo que se passa na privacidade, a diferença entre um idioma formal e a fala comum, como um dispositivo político de exclusão. Nesse caso, não que essas duas linguagens reflitam a heterogeneidade do mundo social quando relacionada à burocracia, mas essa duplicidade pertence ao código que opera essas divisões, podendo fornecer modelos de exclusão e inclusão, a depender tanto da perícia do linguajar jurídico, como da posição de despachante no que se refere à aceleração, ao encurtamento dos prazos. O importante é como os atores se utilizam desses códigos, sua habilidade e posição de uso. Os atores que sabem (e estão na posição de fazê-lo) usam a aparente rigidez do código burocrático para obter o que querem, como a grande gama de intermediários que proliferam na burocracia. Por outro lado, os atores que não obtêm êxito, por inabilidade ou por ocuparem posições de inferioridade no sistema (por não possuir conhecidos ou não dominar o linguajar jurídico), tendem a culpá-lo, a falar mal da burocracia, a tratarem-na como um mal nacional. Uma análise antropológica sobre objetos pouco ortodoxos como o Estado e seu mecanismo comunicacional, a burocracia, deve levar em grande consideração os empregos estratégicos ou práticos de leis e regulamentos. Ainda que o artigo tenha se concentrado na forma como a burocracia quer ser comunicada, procurei também demonstrar a partir de cenas observadas como os desentendimentos sobre as normas representam grande oportunidade de compreensão do funcionamento contextual e prático da burocracia e sua instabilidade inerente diante da tentativa permanente de parecer perene. 


\section{NOTAS}

1 "Não seria possível chegar a outras conclusões, desvelar outros planos mudando este foco de análise, de longe e de fora, com base em outros métodos e instrumentos de pesquisa, como os da antropologia, por exemplo?" (Magnani 2002: 49).

2 Para um maior detalhamento sobre o funcionamento dos cartórios no período colonial e também sobre a forma como se dava a administração colonial, consultar Salgado (1985).

3 Há dois tipos grandes modelos de cartórios, os oficiais e os particulares, se considerada a forma de sua concessão. Cartórios oficiais pertencem ao Estado, possuem funcionários públicos e sua função é fiscalizar os atos dos cartórios particulares. Os cartórios particulares são concessões do Estado a particulares. Nesse tipo de cartório, o serviço é realizado por uma empresa, da qual o tabelião é seu titular e responsável, autorizada pelo Estado e dotado de fé pública, isto é, com presunção de verdade. Os outros serviços que não abordarei são: Serviço de Registro de Títulos e Documentos e Civil das Pessoas Jurídicas, Serviço de Registro Civil das Pessoas Naturais, e Serviço de Registro de Contratos Marítimos e Serviço de Registro de Distribuição. Para um outro ponto de vista acerca dos cartórios como registros da tradição, ver Miranda (2000).

4 Grafarei em itálico as palavras referentes às categorias nativas. Nesse párágrafo, intermediário, amizade, favor e o verbo facilitar vêm destacados também para frisar a relação entre a burocracia, emblema de um sistema público de comunicação e categorias relacionadas mais a domínios particulares. Esse expediente já adianta a visão que se elaborará no artigo acerca da demonstração de procedimentos e estratégias de purificação e hibridização (Latour 2000).

5 Sobre não ser usual antropológos trabalharem em instituições tidas como centrais para a sociedade ocidental - no presente caso, instituições estatais -, Goldman e Lima (1998) apresentam uma interessante reflexão em discussão com Latour (1999).

6 Por motivos éticos não citei a cidade onde foi realizada a pesquisa. Os nomes citados aqui também são fictícios.

7 "Designado" e "concursado", no contexto do cartório, referem-se a dois modos de concessão aos títulares desses serviços. "Concursado" refere-se à seleção mediante concurso público aos bacharéis de direito, ao passo que "designado" se relaciona à concessão sem concurso, muitas vezes obtido como uma forma de herança de algum familiar que ocupava o cargo de titular do tabelionato. Vêm sendo realizados concursos públicos para substituição dos designados pelos concursados; entretanto, não sei informar de forma embasada o motivo de alguns titulares permanecerem de forma designada.

8 Documentos pessoais são documentos utilizados para variados fins (eleitorais, fiscais, policiais, etc) que possuem elementos como números - algumas vezes fotos, outras, assinaturas -, realizando um trabalho de individualização do portador em referência ao estado nacional. Entre os principais documentos desse tipo estão o Registro Geral e o Cadastro de Pessoas Físicas. O primeiro é policial, estadual e relativo à segurança (embora seja usado para variados outros fins) e o último, financeiro, fiscal e nacional. Serão tratados pelas siglas $R G$ e CPF, respectivamente.

9 Abrir ficha no tabelionato significa a fabricação de um documento que o órgão reterá consigo para fins de consulta de assinaturas pela semelhança. É a partir dessas fichas que assinaturas em documentos poderão ser reconhecidas como legitimas e atribuíveis àquele que assinou o documento.

10 Esse atestado pode servir como documento no qual se relata a dependência econômica de uma pessoa com relaçao à outra. Pode ser requerido, por exemplo, por convênios médicos para provar que duas pessoas têm relações conjugais e de dependência econômica sem estarem casados oficialmente.

11 O Fundo de Garantia por Tempo de Serviço é um conjunto de recursos administrado pelo Estado e depositado mensalmente pelos empregadores com a função de amparar os trabalhadores em caso de extinção do contrato de trabalho. Ele também pode ser utilizado pelo trabalhador para adquirir um bem imóvel, desde que o trabalhador não possua nenhum imóvel já registrado em seu nome.

12 Procurações são instrumentos jurídicos pelos quais uma pessoa autoriza outra a agir em seu nome perante alguma instituição. 
13 Segundo os critérios que adotam os tabelionatos, todo cidadão maior e capaz (isto é, lúcido) está autorizado pelo Estado a celebrar contratos. O termo "capaz" foi diversas vezes citado pelos escreventes. Segundo o linguajar jurídico há uma diferença entre capacidade de aquisição, a qual todos detêm desde o nascimento, e a capacidade de exercício, adquirida no transcorrer da vida (na maioridade, por exemplo) e perdida em caso de alguma doença que afete o exercício consciente dessa faculdade.

14 CIRETRAN significa Circunscrição Regional de Trânsito. É o órgão municipal responsável pela aplicação de provas e emissão de carteiras de habilitação. É o braço do Departamento de Trânsito nos municípios. 
CAMPOS, Edmundo (org.). 1971. Sociologia da burocracia, Rio de Janeiro, Zahar.

CARDOSO, Fernando Henrique. 1993. A construção da democracia: estudos sobre a política brasileira. São Paulo: Siciliano.

CROZIER, Michel. 1963. Le phénomène bureaucratique. Paris, Éditions du Seuil.

DA MATTA, Roberto. 1983. Carnavais, malandros e heróis. Rio de Janeiro: Zahar.

1985. “CIDADANIA - A questão da cidadania num universo relacional”. In: A Casa e a Rua. Espaço, Cidadania, Mulher e Morte no Brasil. Rio de Janeiro: Rocco.

DOWNS, Anthony. 1967. Inside bureaucracy. Boston: Little Brown.

FAORO, Raymundo. 2001 [1958]. Os donos do poder: formação do patronato político brasileiro. São Paulo: Globo.

GOODY, Jack. 1986. The logic of writing and the organization of society. Cambridge: Cambridge Unicersity Press.

GOULDNER, Alvin W. 1976. “Conflitos na Teoria de Weber” In: E. Campos (org.). Sociologia da burocracia. Rio de Janeiro: Zahar.

HALL, Richard H. 1976. “O conceito de burocracia: uma contribuição empírica." In: E. Campos (org.). Sociologia da burocracia. Rio de Janeiro: Zahar.

HERZFELD, Michael. 2005 [1997]. Intimidade cultural poética social no Estado-Nação. Lisboa: Edições 70.

IUBEL, Aline. 2009. Sensibilidades e documentos: o movimento de pessoas, fatos e palavras em um direito. Dissertação (Mestrado) - Programa de Pós-Graduação em Antropologia Social, Universidade Federal do Paraná. JAGUARIBE, Hélio. 1958. O nacionalismo na atualidade brasileira. Rio de Janeiro: ISEB.

LATOUR, Bruno. 1999. “Como redividir a Grande Divisão". MOSAICO. Revista de Ciências Sociais 2(1): 168- 175. 2000. Ciência em ação: como seguir cientistas e engenheiros sociedade afora. São Paulo: Editora Unesp. 2004. La fabrique du droit: une etnographie du Conseil d'État. Paris: Éditions La Découverte.

LIMA, Tânia Stolze; GOLDMAN, Márcio. 1998. “Como se faz um grande divisor: etnologia das sociedades indígenas e antropologia das sociedades complexas". Sexta-Feira. Antropologia, Artes, Humanidades 3: 38-45.

MAGALHÃES, Adriana. 2006. "Averbar é preciso.". Jornal O Estado de Minas. Belo Horizonte, 27 de Mar. de 2006. Recuperado em agosto de $2007 \mathrm{de}$ http://www.anoregms.org.br/index.php? $\mathrm{p}=$ detalhe_noticia\&id $=25$

MAGNANI, José G. 2002. “De perto e de dentro: nota para uma etnografia urbana." Revista Brasileira de Ciências Sociais (ANPOCS) 17 (49): 11-29.

MERTON, Robert K. 1976. "Estrutura Burocrática e Personalidade." In: E. Campos (org.). Sociologia da burocracia. Rio de Janeiro: Zahar.

MIRANDA, Ana Paula Mendes de. 2000. “Cartório: onde a tradição tem registro público". Antropolítica: Revista Contemporânea de Antropologia e Política 8(1): 59-75.

PEIRANO, Mariza. 2002. "This horrible time of papers: documentos e valores nacionais". Série Antropologia 312: 1-61. 
PRESTES MOTTA, Fernando C. 1981. Burocracia e autogestão: aproposta de Proudhon. São Paulo: Brasiliense. REIS, Eliza. P. 1990. "A opressão burocrática: o ponto de vista do cidadão”. Estudos Históricos 3: 161-179. SALGADO, Graça (coord.). 1985. Fiscais e meirinhos: a administração no Brasil Colonial. Rio de Janeiro: Nova Fronteira.

SCHWARTZ, Stuart B. 1979. Burocracia e sociedade no Brasil colonial. São Paulo: Perspectiva.

SOUZA LIMA, Antônio Carlos. 2002. Gestar e gerir: estudos para uma antropologia da administração pública no Brasil. Rio de Janeiro: Relume-Dumará.

TULLOCK, Gordon. 1965. The politics of bureaucracy. New York, University Press of America.

WEBER, Max. 1976. "Os fundamentos da organização burocrática: uma construção do tipo ideal.". In: E. Campos (org.). Sociologia da burocracia. Rio de Janeiro: Zahar. 


\section{Um antropólogo no cartório: o circuito dos documentos}

\section{RESUMO}

O artigo reflete sobre o modus operandi da burocracia estatal brasileira, por meio de pesquisa de campo em um tabelionato de notas e o acompanhamento de pessoas na busca por documentos emitidos por cartórios. Procura-se pensar sobre os aspectos formais e informais no processo de fabricação de documentos: o constante e obrigatório remeter a outros documentos, o papel dos conhecidos junto a organizações burocráticas estatais, além de outras categorias nativas como segurança, confiança e responsabilidade. Inspirado nas leituras de Latour sobre a ciência e o direito e o modo de construção desses saberes na prática, concebe-se toda a circulação de documentos, palavras e pessoas como uma forma de comunicação engendrada pela burocracia.

PALAVRAS-CHAVE: Antropologia; Sociedade brasileira; Burocracia; Comunicação; Documentos

\section{An anthropologist at a public notary's office: a circuit of documents}

\section{ABSTRACT}

This article studies the modus operandi of Brazilian state bureaucracy through ethnographic research of a public notary's office and its users. It aims at discussing formal and informal aspects of the process of making documents, such as the constant and obligatory references to other documents; the role of the acquaintances in the state bureaucratic organizations; and some native categories such as security, trust and responsibility. Inspired by Bruno Latour's studies on science and law, which focus on how these types of knowledge are constructed in practice, the text analyses the circulation of documents, words and people as a form of communication engendered by bureaucracy.

KEYWORDS: Anthropology; Brazilian society; Bureaucracy; Communication; Documents. 